\title{
Evaluation of patient perceptions after labial frenectomy procedure: A comparison of diode laser and scalpel techniques
}

\author{
Kalakonda Butchibabu, Pradeep Koppolu, Ashank Mishra, Ruchi Pandey, \\ Lingam Amara Swapna ${ }^{1}$, Uday Kiran Uppada ${ }^{2}$ \\ Departments of Periodontics, ${ }^{1}$ Oral Medicine and Radiology and ${ }^{2}$ Oral and Maxillofacial Surgery, \\ Sri Sai College of Dental Surgery, Vikarabad, Andhra Pradesh, India
}

\author{
Address for correspondence: \\ Dr. Kalakonda Butchibabu, \\ Department of Periodontics, \\ Sri Sai College of Dental Surgery, \\ Vikarabad, Andhra Pradesh, India. \\ E-mail: docbutchi@gmail.com
}

\begin{abstract}
Background: Frenectomy is the complete excision of the frenum along with its attachment to the underlying bone. It can be done by conventional technique, electrosurgery or soft tissue lasers. Aim: To evaluate the effects of diode laser and scalpel technique on degree of post-operative pain and discomfort experienced by patients on the $1^{\text {st }}, 3^{\text {rd }}$ and the $7^{\text {th }}$ post-operative days after frenectomy. Materials and Methods: Ten patients who required frenectomy were randomly assigned to undergo treatment with diode laser or scalpel. The data were analyzed with paired $t$-test and intragroup comparison was determined by ANOVA. Results: Intergroup comparison of the mean VAS scores for discomfort and pain for both the groups showed significant difference. The VAS scores of pain and discomfort within scalpel group between $1^{\text {st }}$ and $3^{\text {rd }}$ day did not show any significant difference, however between $7^{\text {th }}$ day versus $3^{\text {rd }}$ and $1^{\text {st }}$ day difference was highly significant. The VAS scores of pain and discomfort within laser group between all the days showed significant difference. Conclusion: Taking into consideration the clinical outcome, the diode laser is a dependable alternative as it is an efficient and satisfactory option for procedures like frenectomy.
\end{abstract}

Key words

Diode laser, frenectomy, scalpel

\section{INTRODUCTION}

A frenum is a fold of mucous membrane, generally through enclosed muscle fibers, that attaches the lips and cheeks to the alveolar mucosa and/or gingiva and underlying periosteum. ${ }^{[1]} \mathrm{A}$ frenum that is closely attached to the gingival margin would compromise the health of the gingiva either by not permitting proper placement of a tooth brush resulting in poor oral hygiene practice and by muscle pull leading to opening of the gingival sulcus eventually leading to gingival recession and midline diastema, which may be of high esthetic concern and sometimes leading to speech difficulties. ${ }^{[2]}$ The facial surface between the maxillary and mandibular central incisors along with canine and premolar areas is the area that is most prone to frenal problems. ${ }^{[3]}$

\begin{tabular}{|l|l|}
\hline \multicolumn{2}{|c|}{ Access this article online } \\
\hline Quick Response Code: & Website: \\
\hline & www.ejgd.org \\
\cline { 2 - 2 } & \\
\hline
\end{tabular}

Removal of the abnormal frenum is facilitated by either frenotomy or frenectomy. Frenotomy is the incision and relocation of the frenal attachment, whereas frenectomy is the complete excision of the frenum along with its attachment to the underlying bone. ${ }^{[2]}$ Frenectomy can be done by conventional technique, electrosurgery or soft tissue lasers. ${ }^{[4,5]}$ Among the various lasers, $\mathrm{CO}_{2}$ and neodymium-doped yttrium aluminum garnet (Nd: YAG) have been quite efficient in soft tissue surgeries such as gingivectomy, frenectomy etc., ${ }^{[6,7]}$ The aim of this study was to evaluate the effects of diode laser or scalpel technique on the degree of postoperative pain and discomfort experienced by patients on the $1^{\text {st }}, 3^{\text {rd }}$ and the $7^{\text {th }}$ postoperative days after frenectomy.

\section{MATERIALS AND METHODS}

The study sample was selected from among patients who had been referred to various private clinics between July 2013 and September 2013. Systemically healthy patients with maxillary papillary or papillary penetrating type frenal attachment were only included.

Ten patients who required frenectomy were randomly assigned to undergo treatment with diode laser or scalpel group with five patients in each group. Informed written 
consent was obtained from all the patients. Six males and four females with age ranging from 18 to 30 years were included in the study.

For the conventional technique, after sufficient anesthesia was achieved once the area was anesthetized with $2 \%$ lignocaine with 1:80,000 adrenaline [Figure 1], the frenum was held with a hemostat engaging to its full depth and excision was carried out removing the frenum along with its alveolar attachment using a No. 15 blade [Figure 2]. The wound was closed using 3-0 silk interrupted sutures [Figure 3].

For the laser technique, a diode laser (Sunny, MSI, Bengaluru) with an $808 \mathrm{~nm}$ wavelength was used. A $300 \mu \mathrm{m}$ fiber with an initiated tip at $1.5-2 \mathrm{~W}$ continuous mode was used. Prior to the laser assisted excision procedure, surface anesthesia was achieved with a topical gel applied with small cotton pellets over the frenum [Figure 4]. For patients who still had complained of pain during the procedure, a small amount of local anesthetic was infiltrated in the vicinity of the frenum. After the frenum was engaged with a pair of hemostats, the laser fiber tip was used in a contact mode and moved, in a paint brush stroke, from the base to the apex of the frenum thereby excising it. Postirradiation with the laser tip, any remnant fibers over the periosteum were removed by gently

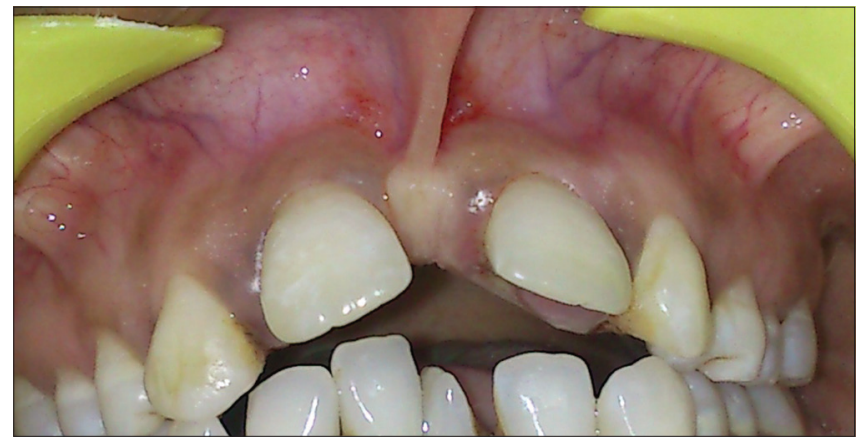

Figure 1: Preoperative figure showing papillary penetrating frenum

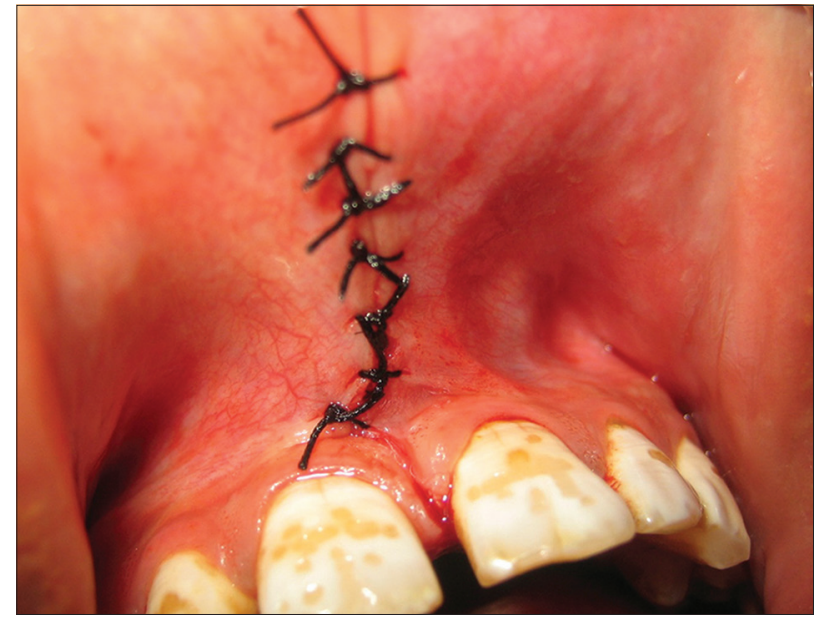

Figure 3: Suturing of the site sweeping the laser tip at a reduced power and the ablated remnant tissue was cleaned with gauze soaked in saline [Figure 5]. Sutures were not given post the laser treatment. Both groups received postoperative instructions and the use of any analgesic was left to the patient's discretion.

\section{Method of scoring}

The patients were asked to separately rate the pain and discomfort associated with eating and chewing on a $100 \mathrm{~cm}$ visual analog scale (VAS) immediate postoperatively, $3^{\text {rd }}$ day and $7^{\text {th }}$ day.

The patient was asked to make a vertical mark between two endpoints on the pain scale. Related to the pain scale, the left end point was nominated as "no pain," whereas the right end point was nominated as "worst pain imaginable." Regarding the discomfort scale associated with chewing and speech, the two endpoints were nominated as "no discomfort" on the left side and "extreme discomfort" on the right side. A single trained operator was engaged in recording the scores.

\section{Statistical analysis}

Statistical analysis was performed using IBM Statistical Program for Social Sciences Version 17.0 (SPSS Inc, Chicago Illinois, USA). The statistical significance of data for all pain and discomfort scores between the groups was determined by the paired $t$-test and intragroup

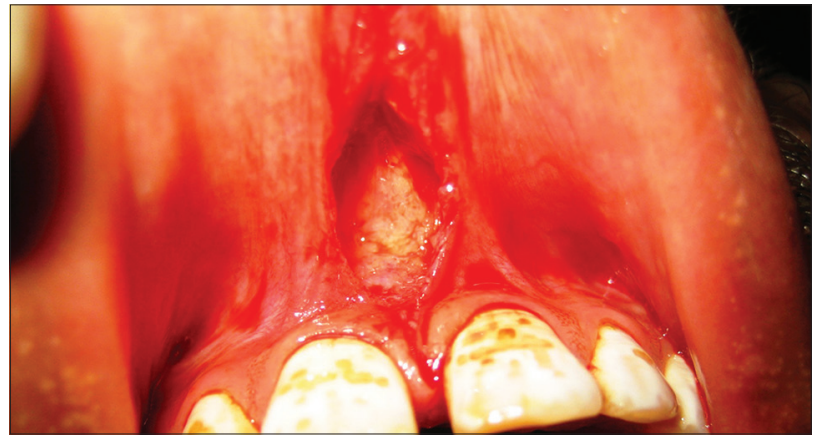

Figure 2: After excision of the frenum with scalpel

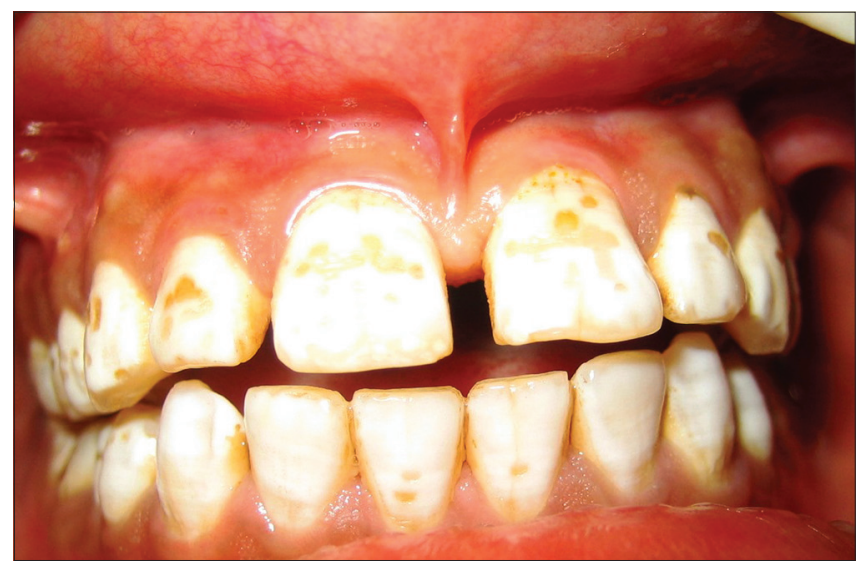

Figure 4: Preoperative figure showing papillary penetrating frenum 
comparison was determined by ANOVA. Changes were considered significant at the $P<0.05$ levels and highly significant at the $P<0.001$.

\section{RESULTS}

A total of 10 subjects were enrolled in the study and all of them completed both the comparisons. Comparison of the mean VAS scores of the levels of pain, for both groups, observed on the $1^{\text {st }}, 3^{\text {rd }}$ and the $7^{\text {th }}$ day of the study is summarized in Table 1 and Figure 6. Analysis showed that there was a significant difference in VAS scores of pain, when both the treatment methods are compared on the $1^{\text {st }}, 3^{\text {rd }}$ and the $7^{\text {th }}$ day $(P<0.05)$, with the laser group displaying significantly lower VAS scores.

Comparison of the mean VAS scores for discomfort associated with speaking and chewing, for both groups, observed on the $1^{\text {st }}, 3^{\text {rd }}$ and the $7^{\text {th }}$ day of the study is summarized in Table 2 and Figure 7. Further analysis suggested that there was a significant difference of the VAS scores of discomfort associated with chewing and speaking between both groups on the $1^{\text {st }}, 3^{\text {rd }}$ and the $7^{\text {th }}$ days, with the laser group displaying significantly lower VAS scores.

Table 3 analyzes the intragroup comparison of pain and discomfort VAS scores within the scalpel group. The VAS scores of pain and discomfort on the $3^{\text {rd }}$ day did not show any significant difference when compared with those on the $1^{\text {st }}$ day. However, when the scores from the $7^{\text {th }}$ day were compared with those on the $3^{\text {rd }}$ and the $1^{\text {st }}$ day, a highly significant difference was found $(P<0.001)$.

Table 4 analyzes a similar comparison within the laser group. However, within the laser group, the difference in the VAS scores of pain and discomfort on the $1^{\text {st }}, 3^{\text {rd }}$ and the $7^{\text {th }}$ days, when compared with one another, were found to be highly significant $(P<0.001)$.

\begin{tabular}{|c|c|c|c|}
\hline & Scalpel & Laser & $P$ value \\
\hline $1^{\text {st }}$ day & $87.6000 \pm 5 \cdot 59$ & $65.00 \pm 4.30$ & $0.002 *$ \\
\hline $3^{\text {rd day }}$ & $79.800 \pm 7.91$ & $37 \cdot 40 \pm 5 \cdot 45$ & $0.005^{*}$ \\
\hline $7^{\text {th }}$ day & $37.0000 \pm 4.69$ & $13.8 \pm 3.86$ & $0.02^{\#}$ \\
\hline
\end{tabular}

\begin{tabular}{|c|c|c|c|}
\hline & Scalpel & Laser & $P$ value \\
\hline $1^{\text {st }}$ day & $81.8000 \pm 4.96$ & $53.80 \pm 4.86$ & $0.001 *$ \\
\hline $3^{\text {rd day }}$ & $74.6000 \pm 4.72$ & $30.80 \pm 6.79$ & $0.001 *$ \\
\hline $7^{\text {th }}$ day & $21.0000 \pm 2.91$ & $7.40 \pm 2.40$ & $0.001 *$ \\
\hline
\end{tabular}

\section{DISCUSSION}

Patients who undergo conventional frenectomy procedures using a scalpel often experience postsurgical pain and discomfort, which is further aggravated when sutures come in contact with food. One feasible alternative that can be considered is a laser, as it offers various advantages, that is, relatively bloodless surgery, sterilization of wound, no suturing required in most cases, less surgical time, periodontal dressing not required, less postsurgical pain and discomfort and increased patient acceptance. ${ }^{[8-11]}$

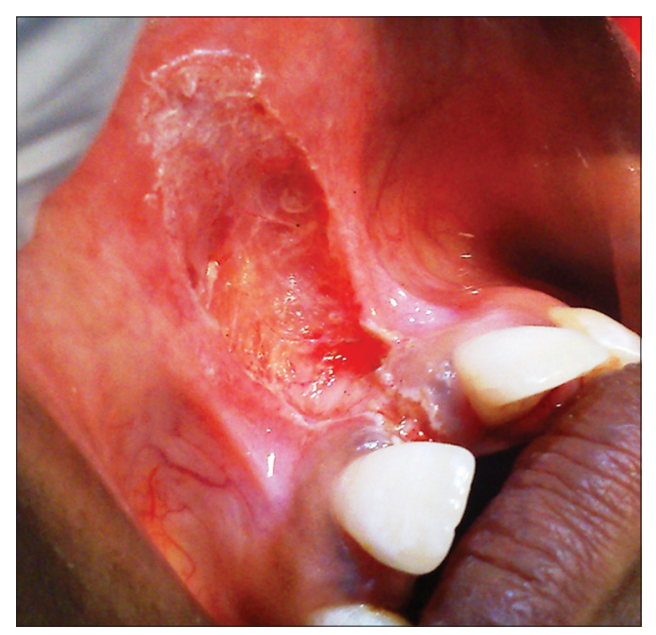

Figure 5: Excision of the frenum with laser

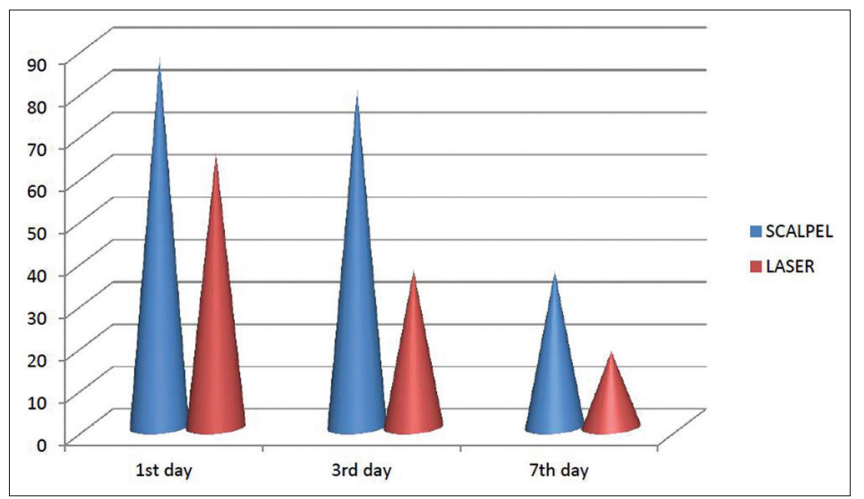

Figure 6: Intergroup comparison of visual analog scale scores of pain

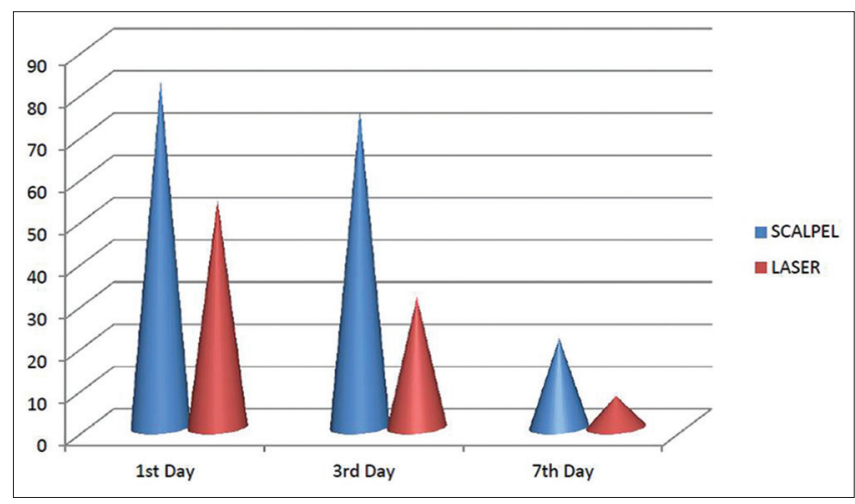

Figure 7: Intergroup comparison of visual analog scale scores of discomfort 
Lasers such as $\mathrm{Nd}$ : YAG, $\mathrm{Co}_{2}$, and erbium: YAG had been used for frenectomy procedures. Among these, $\mathrm{Co}_{2}$ laser was the most frequently used one. In the present study diode laser, which characteristically uses a blend of gallium, arsenide, and other elements such as aluminum and indium was used. The wavelength of this laser is feebly absorbed in water, but extremely absorbed in hemoglobin and other pigments. As diode laser is considered as an excellent soft tissue laser as it doesn't interact with dental hard tissues. Smaller size of units and lower financial costs are few other advantages. ${ }^{[12]}$

There are indeed a not many studies comparing the postoperative effects of diode laser and scalpel postfrenectomy. Kara ${ }^{[13]}$ compared Nd: YAG laser to conventional scalpel surgery and reported that patients treated with laser reported higher levels of satisfaction, less postsurgical pain and discomfort. Haytac and Ozcelik ${ }^{[6]}$ compared 20 frenectomy procedures performed with $\mathrm{Co}_{2}$ laser to an equal number performed with conventional scalpel surgery and reported that patients treated with laser experienced less pain after $1^{\text {st }}$ day and $7^{\text {th }}$ day.

In this study, it was observed that patients treated with the diode laser experienced less pain and discomfort

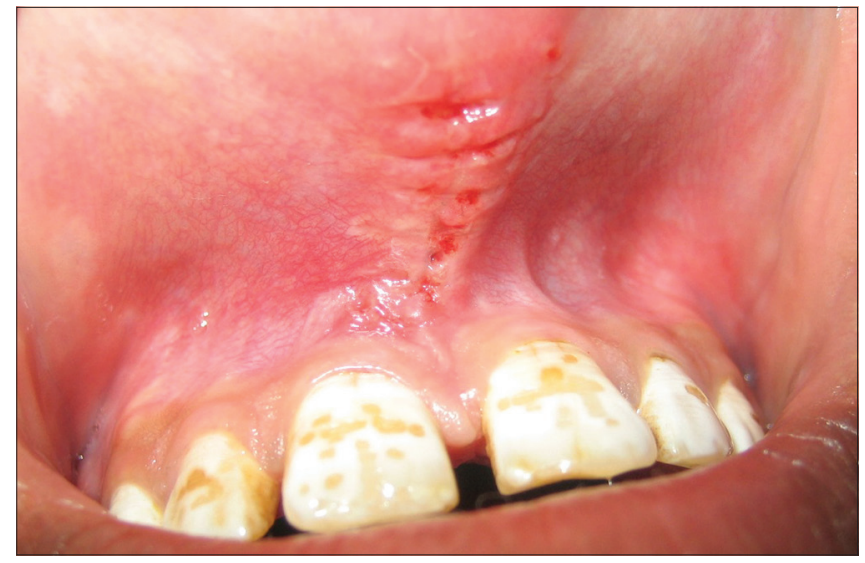

Figure 8: One week postoperative view of the site when compared with those treated with scalpel. It has also been observed that the reduction in pain and discomfort levels from the $1^{\text {st }}$ to the $3^{\text {rd }}$ and further to the $7^{\text {th }}$ day is much more significant for the laser group. The increased pain perception associated with the scalpel frenectomy might be attributed to the fact that it is a more intrusive surgical procedure involving blood loss, wide surgical wound and suturing [Figure 8]. The sutures also contribute to the discomfort postoperatively since they interfere with regular functions such as speech and intake of food.

On the contrary, the decreased pain and discomfort in the laser group might be ascribed to the protein coagulum formed over the wound, which acts like a biological dressing, aids in sealing of the ends of sensory nerves. ${ }^{[14,15]}$ Absence of any sutures post the laser procedure might have contributed to lesser discomfort levels [Figure 9]. There have been a number of prior studies that corroborated that lasers cause less bleeding with minimal scarring, less postoperative pain and a minimal number of cases requiring suturing with quicker wound healing. ${ }^{[7-10]}$

Although the decision to use an analgesic was left to the patient's discretion, an observational study was done to analyze the use of analgesics in both the groups. The

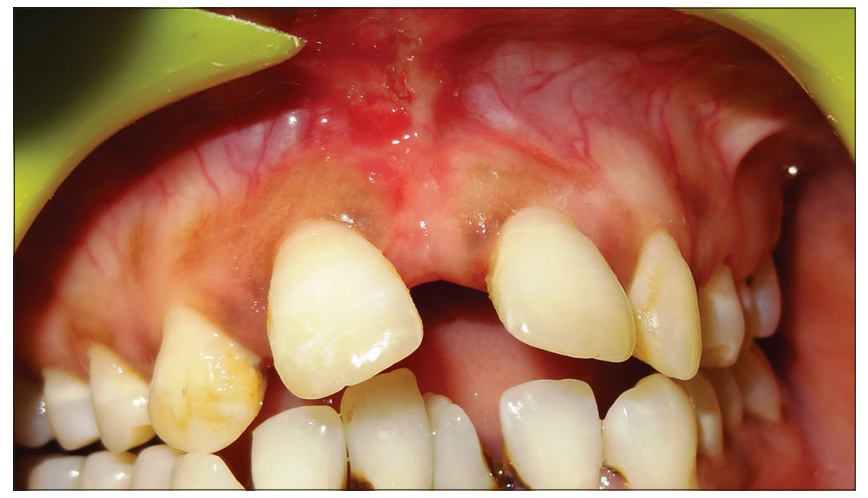

Figure 9: One week postoperative view

\begin{tabular}{|c|c|c|c|c|c|c|}
\hline Scalpel group & Pain & Comparision & $P$ value & Discomfort & Comparision & $P$ value \\
\hline $1^{\text {st }}$ day & $87.6000 \pm 5.59$ & $1^{\text {st }}$ day versus $3^{\text {rd }}$ day & $0.159^{\#}$ & $81.8000 \pm 4.96$ & $1^{\text {st }}$ day versus $3^{\text {rd }}$ day & 0.052 \\
\hline $3^{\text {rd day }}$ & $79.800 \pm 7.91$ & $3^{\text {rd }}$ day versus $7^{\text {th }}$ day & $0.001 *$ & $74.6000 \pm 4.72$ & $3^{\text {rd }}$ day versus $7^{\text {th }}$ day & $0.001^{*}$ \\
\hline $7^{\text {th }}$ day & $37.0000 \pm 4.69$ & $1^{\text {st }}$ day versus $7^{\text {th }}$ day & $0.001 *$ & $21.0000 \pm 2.91$ & $1^{\text {st }}$ day versus $7^{\text {th }}$ day & $0.001 *$ \\
\hline
\end{tabular}

"P>0.05: Statistically not significant $* P<0.001$ : Statistically highly signifi cant. VAS $-V$ isual analog scale

\begin{tabular}{|c|c|c|c|c|c|c|}
\hline Laser group & Pain & Comparision & $P$ value & Discomfort & Comparision & $P$ value \\
\hline $1^{\text {st }}$ day & $65.00 \pm 4.30$ & $1^{\text {st }}$ day versus $3^{\text {rd }}$ day & $0.001 *$ & $53.80 \pm 4.86$ & $1^{\text {st }}$ day versus $3^{\text {rd }}$ day & $0.001 *$ \\
\hline $3^{\text {rd day }}$ & $37.40 \pm 5.45$ & $3^{\text {rd }}$ day versus $7^{\text {th }}$ day & $0.001 *$ & $30.80 \pm 6.79$ & $3^{\text {rd }}$ day versus $7^{\text {th }}$ day & $0.001 *$ \\
\hline $7^{\text {th }}$ day & $18.0 \pm 4.0$ & $1^{\text {st }}$ day versus $7^{\text {th }}$ day & $0.001 *$ & $7.40 \pm 2.40$ & $1^{\text {st }}$ day versus $7^{\text {th }}$ day & $0.001 *$ \\
\hline
\end{tabular}


study revealed that among the five patients considered for each group, only one patient (20\%) from the laser group used an analgesic whereas three (60\%) of the scalpel group patients used an analgesic.

\section{CONCLUSION}

The results presented in this paper support the use of diode lasers in soft tissue procedures like frenectomy. Diode lasers provide better patient perception in terms of reduced operative time, pain, and discomfort than that obtained by the scalpel technique. Taking into consideration the admirable clinical outcome, the diode laser is a dependable alternative as it is an efficient, secure, and satisfactory option for soft tissue surgeries like frenectomy.

\section{REFERENCES}

1. Devishree, Gujjari SK, Shubhashini PV. Frenectomy: A review with the reports of surgical techniques. J Clin Diagn Res 2012;6:1587-92.

2. Takei HH, Azzi RA. Periodontal plastic and esthetic surgery. In: Newman MG, Carranza FA, editors. Carranza's Clinical Periodontology. London: W.B. Saunders; 2002. p. 870-1.

3. Whinston GJ. Frenotomy and mucobuccal fold resection used in periodontal therapy. NY Dent J 1956;22:495.

4. Pick RM, Colvard MD. Current status of lasers in soft tissue dental surgery. J Periodontol 1993;64:589-602.

5. Research, Science and Therapy Committee of the American Academy of Periodontology. Lasers in periodontics. J Periodontol 2002;73:1231-9.

6. Haytac MC, Ozcelik O. Evaluation of patient perceptions after frenectomy operations: A comparison of carbon dioxide laser and scalpel techniques. J Periodontol 2006;77:1815-9.

7. Schuller DE. Use of the laser in the oral cavity. Otolaryngol Clin North Am 1990;23:31-42.

8. Pick RM, Pecaro BC. Use of the $\mathrm{CO}_{2}$ laser in soft tissue dental surgery. Lasers Surg Med 1987;7:207-13.

9. Wigdor HA, Walsh JT Jr, Featherstone JD, Visuri SR, Fried D, Waldvogel JL. Lasers in dentistry. Lasers Surg Med 1995;16:103-33.

10. Bader HI. Use of lasers in periodontics. Dent Clin North Am 2000;44:779-91.

11. Schwarz F, Aoki A, Sculean A, Becker J. The impact of laser application on periodontal and peri-implant wound healing. Periodontol 2000 2009;51:79-108.

12. Desiate A, Cantore S, Tullo D, Profeta G, Grassi FR, Ballini A. $980 \mathrm{~nm}$ diode lasers in oral and facial practice: Current state of the science and art. Int J Med Sci 2009;6:358-64.

13. Kara C. Evaluation of patient perceptions of frenectomy: A comparison of Nd: YAG laser and conventional techniques. Photomed Laser Surg 2008;26:147-52.

14. Fisher SE, Frame JW, Browne RM, Tranter RM. A comparative histological study of wound healing following $\mathrm{CO}_{2}$ laser and conventional surgical excision of canine buccal mucosa. Arch Oral Biol 1983;28:287-91.

15. Fenner J, Martin W, Moseley H, Wheatley DJ. Shear strength of tissue bonds as a function of bonding temperature: A proposed mechanism for laser-assisted tissue welding. Laser Med Sci 1992;7:39-43.

How to cite this article: Butchibabu K, Koppolu P, Mishra A, Pandey R, Swapna LA, Uppada UK. Evaluation of patient perceptions after labial frenectomy procedure: A comparison of diode laser and scalpel techniques. Eur J Gen Dent 2014;3:129-33.

Source of Support: Nil, Conflict of Interest: None declared. 